\title{
The Passion of Ignorance
}

\section{Review by Lucy Holmes}

Dany Nobus and Malcolm Quinn, Knowing Nothing, Staying Stupid: Elements for a Psychoanalytic Epistemology. London: Routledge, 2005.

I 2006, 3-4 July. Association for Tertiary Education Managers, New Zealand Branch Conference. Bay of Plenty Polytechnic, Tauranga. Kuni Jenkins is Interim Chief Executive Officer of $\mathrm{Te}$ Whare Wanaanga o Awanuiarangi, Whakatane.
At a conference on tertiary education management, in July 2006, Kuni Jenkins mentioned Lacanian psychoanalysis and its principle of the passion of ignorance. ${ }^{1} \mathrm{~A}$ leading academic making a place for ignorance seems surprising, as does reference to a field of psychoanalysis yet to find a place, either as theory or as clinical practice, in a New Zealand tertiary institution.

The first chapter of Knowing Nothing, Staying Stupid intimates why this may be so. The analyst's passion of ignorance is defined, not as the absence of knowledge, but as the recognition of the limits of knowledge: as knowledge does not hold all the answers, so the analyst's knowledge must not be presented as the truth about the patient (25-26). Lacanian psychoanalysis focuses not only on the speech of each unique person within a specific social formation, but also on how speech is unconsciously marked by the satisfaction and suffering driving the subject's words. Nobus and Quinn's book links these clinical concerns to epistemology, making the case that the unconscious presents us with the limits of our knowledge; its truth is the "human being's incapacity to master all knowledge owing to the absence of a knowing agency at the level of the unconscious" (49). In the context of tertiary education, to speak of the passion of ignorance implies a challenge to education to account for the 'other' of academic reason.

In contrast to a Lacanian epistemology, contemporary universities tend to rationalise all knowledge in terms of its market value whose goal is social and economic success (121-122). This implicit denial of the failure and fall of knowledge results in a mania for progress and completion, paradoxically working to hinder the development of academic knowledge (196). Similar criticisms have been made of New Zealand tertiary education; the knowledge economy provides more funds for those bodies of knowledge "that support competition and economic growth" (Harvey, 2003: 4).

Using Lacan's discourse theory, Nobus and Quinn explain how the discourse of the university always serves a master - in this case the economy and the market place of ideas. Their book explains an important difference between those discourse theories in which ideology finds its support in the social practice of language, and Lacan's “discourses [which] are not to be used as keys to the meaning of speech, but as a means of separating speech from meaning" (2005: 128). This separation makes explicit a distinction between the truth of the unconscious as a causal function that "drives and structures speech", and the view upheld by the knowledge economy of "truth as a consciously achieved effect" (132). The conscious use of speech aims to convey a certain meaning. However, the unconscious undermines intended meaning and its reception; thus, communication entails its failure, no matter how skilled the speaker.

In Knowing Nothing, Staying Stupid, the role of applied psychoanalysis, and how it might avoid being yet another interpretive procedure servicing the market place, 
is a key question. Nobus and Quinn present various philosophical and artistic hoaxes - Žižek, Sokal and Duchamp - to explain how the logic of the unconscious redirects the search for an interpretive truth. Žižek's hoax involved his interpretation of a painting about which he knew nothing. However, his listeners, at an art round table, accepted it as a successful interpretation. The hoax is used in his critique of cultural studies' use of theory to highlight the "radical apathy at the very heart of today's cultural studies" (Žižek, 2001: 6, 130). Adding a further twist to the critique, Nobus and Quinn point out that Žižek falls into his own trap when he later applies the same interpretative approach as a legitimate method; thus the critical force of the hoax is lost, changing neither "the relations of 'The Žižekian field' that secured him a place at the art round table", nor "the relations within the market place of ideas in which the public discourse on art and psychoanalysis is contained" (2005: 178). As Žižek's readers, we are in the same position as the participants of the art round table, uncritically accepting interpretative mastery. This is a position shared by the editors of the journal Social Text when they accepted Alan Sokal's paper on the basis of the author's credentials, despite his fraudulent use of cultural theory. Sokal disturbed the realm of academic reason by showing that cultural theory (including postmodernism and Lacanian theory) is nonsense, a mistaken belief. However, Nobus and Quinn claim that the consequence of Sokal's hoax demonstrates that "the exchange of nonsense" is able to make perfect sense (190). The affair underlined how the stupidity of signifiers (i.e., the style of theory-speak used by Sokal) constructed an artifice, a fabrication, effectively exposing the manoeuvres of academic speech for which there are no "academic subjects to speak, receive, or understand it" (181). The consequences of the hoax exemplify the Lacanian theory of discourse, where the separation of speech from meaning may produce an effect that the author did not intend: Sokal, unwittingly, proved that Lacan makes sense.

Knowing Nothing, Staying Stupid examines the effects of the hoax on an institutional critique. Pierre Bourdieu's admission that his institutional critique ironically perpetuated the success of those institutions, introduces a discussion of Duchamp's submission to the New York Independents' Show as an intervention leading to institutional failure and the fall of knowledge. Rather than contributing to the Independents' Show's progressive aims - of allowing anyone to enter an art show - Duchamp's action averted institutional and discursive ideals by highlighting progress' latent possibility of failure (184). For Nobus and Quinn, this action operates in the same way as the psychical object or artifice, which is constructed on the basis of the unconscious effects in speech, and on which the patient's fantasy is articulated and traversed. The analyst's position of misunderstanding, of playing the dummy hand - as with the gap made by the work of art - deflects the patient's request for interpretation, allowing space for a strange nonrelational form of knowledge at the limits of representational systems.

This book's critical potential lies in its advocacy of a form of knowledge "that is no longer relational, that essentially disrupts the relational quality of any discursive structure" (5). The unconscious occurs in the discontinuities of speech, thought and action, and interrupts communication between self and others. The non-relational stupidity of the unconscious may seem regressive when compared with the emphasis on the intersubjective in certain social constructivist theories and relational aesthetics. A psychoanalytic epistemology is concerned with what 
2 Sharon Harvey's criticism of the New Zealand knowledge society makes a similar argument when she points out that academics tend to decry the processes of the knowledge economy, but are less concerned with the "destination" of knowledge that advances the globally competitive market place (2003: 5) continually prevents the full realisation, or closure, of relationality, and instead takes into account the resistances to meaning where the search for knowledge about self and other fails.

Knowing Nothing Staying Stupid concludes by addressing the question of what use Lacanian psychoanalysis is, if it does not improve interpretive methodologies. Rather than providing a hermeneutical model, a psychoanalytic epistemology offers another paradigm where, like Duchamp's intervention,

an apparently negative or spurious act, which seems to invent problems where none exist, or which fails to respect the wish for knowledge to 'move on' in search of the latest epistemological trends, is precisely what is needed in order to link knowledge to its effects (197).

In the context of a local and global focus on the society of knowledge, in which research is increasingly measured by its market value, the consequences of knowledge become less creative and more constrained. ${ }^{2}$ An alternative approach to an ethics of knowledge allows for the passion of ignorance, the moment when the failure of knowledge has creative and critical effects.

\section{References}

Dyess, C. and Dean, T. (2000). Gender: The impossibility of meaning. Psychoanalytic Dialogues, 10, 735-756.

Harvey, S. (2003). For knowledge society read knowledge economy? One future for tertiary education in New Zealand. Retrieved 26 June, 2005, from http://surveys.canterbury. ac.nz/herdsa03/pdfsref/Y1076.pdf

Žižek, S. (2001). The fright of real tears: Krzysztof Kieślowski between theory and post-theory. London: British Film Institute. 